\title{
The effects of bilingualism on the structure of the hippocampus and on memory performance in ageing bilinguals
}

\author{
Toms Voits ${ }^{\mathrm{a}}$, Holly Robson ${ }^{\mathrm{a}}$, Jason Rothman ${ }^{\mathrm{b}, \mathrm{c}}$, and Christos Pliatsikas ${ }^{\mathrm{a}, \mathrm{c}}$ \\ aSchool of Psychology and Clinical Language Sciences, University of Reading, Harry Pitt Building, Earley Gate, \\ Whiteknights Road, Reading, RG6 6AL, UK. \\ ${ }^{b}$ Department of Language and Culture, The University of Tromsø, Hansine Hansens veg 18, 9019, Tromsø, Norway \\ 'Facultad de Lenguas y Educación, Universidad Nebrija, Calle de Sta. Cruz de Marcenado, 27, 28015, Madrid, Spain
}

\begin{abstract}
Long-term management of more than one language has been suggested to lead to changes in cognition and the brain. This is particularly documented in older age, where bilingualism is associated with protective effects against decline, for example, affording compensation for symptoms of Alzheimer's disease leading to delayed diagnosis relative to non-bilinguals. Herein, we focus on potential bilingualism effects in the hippocampus, a brain structure related to memory that is particularly vulnerable to cognitive ageing. Hippocampal volume has been shown to increase as a result of second language learning and use in younger adults. However, we do not know if this is maintained over the lifespan, that is, what the long-term effects might be examined in ageing. Herein, we examine hippocampal volume and performance in episodic memory tasks in healthy ageing long-term bilinguals compared to monolinguals. Results show greater hippocampal volume for the bilinguals, which was correlated to individual-level quantified use of the two languages. Thus, our results mirror that of immersive active bilingualism in younger populations. No significant effects of bilingualism were reported on episodic memory task performance. Our findings suggest that long-term active bilingualism leads to neuroprotective effects in the hippocampus, which we discuss in the context of the proposed bilingualism-induced brain reserve in older age literature.
\end{abstract}

Keywords: bilingualism, ageing, memory, hippocampus 


\section{Introduction}

The experience of being a bilingual has been shown to have an impact on domain general cognition (e.g., Marian \& Shook, 2012), in particular in the domain of executive functions (Bialystok, Craik, Klein, \& Viswanathan, 2004; Bialystok, Craik, \& Luk, 2008) and episodic memory performance (Schroeder \& Marian, 2012). It has also been shown to be a source of neural plasticity. Specifically, increased cognitive control demands associated with management of more than one language result in structural and functional adaptations in brain regions comprising networks related to language acquisition and processing, as well as domain general cognitive control (e.g., Grundy et al., 2017; Pliatsikas, 2019). Notably, and although bilingualism effects can be observed across the lifespan, effects on behaviour are more robustly observed in ageing populations. Specifically, ageing bilinguals outperform monolinguals in task testing executive functioning (e.g., Bialystok, Craik, Klein, \& Viswanathan, 2004; Sullivan, Prescott, Goldberg, \& Bialystok, 2016), a set of cognitive control processes, such as mental set shifting, updating, and inhibition (Miyake et al., 2000). With regard to neuroanatomical changes in these age groups, bilingualism has been associated with greater grey matter volume and white matter integrity across brain structures involved in bilingual language control, language learning, and language processing (Anderson, Grundy, et al., 2018; Duncan et al., 2018; Gold, Kim, Johnson, Kryscio, \& Smith, 2013). The findings regarding beneficial effects of bilingualism on the ageing brain and cognition are of particular importance, as it is the same period in life where cognition and the brain are expected to decline; therefore, it is interesting to investigate how the effects of bilingualism interact with those of ageing. The following section will provide a brief overview of our current knowledge on the effects of ageing and bilingualism on the brain with a particular focus on episodic memory and a key brain region that underlies it, the hippocampus. This will be followed by evidence on how these effects might interact, including the underlying mechanisms.

Overall, general cognition, including episodic memory, and the supporting neural architecture, are subject to decline in the older age, otherwise referred to as cognitive ageing. At the brain level, cognitive ageing is perhaps most clearly identifiable in anatomical brain changes such as reductions in grey matter (GM) volume and/or white matter (WM) integrity, especially in the prefrontal cortex and hippocampus, and/or decreased efficiency (i.e. increased recruitment of implicated networks) in task performance (e.g., Bettio, Rajendran, \& GilMohapel, 2017; Farokhian, Yang, Beheshti, Matsuda, \& Wu, 2017; Giorgio et al., 2010; Nyberg et al., 2010; Persson et al., 2006; Rönnlund, Nyberg, Bäckman, \& Nilsson, 2005). 
However, there is a general variability in cognitive ageing trajectories across the population. Some individuals seem to be more resilient to cognitive decline in the older age. In addition to genetic factors as determinants of individual differences (e. g. possession of the $A P O E$ e4 allele or polygenic scores), this variability can be explained by the concepts of cognitive reserve, brain reserve, and brain maintenance (Stern et al., 2018). Cognitive reserve refers to preserved cognitive ability in the face of neural damage or neurodegeneration and can manifest as betterthan-expected cognition in cases of progressive neurodegeneration. Brain reserve, however, refers to the build-up of neural tissue, as a structural reinforcement of the brain, via volumetric increases caused by neurogenesis or dendritic branching. This added neural tissue then acts as a reinforcing scaffolding, meaning that the neurodegenerative processes need to take longer before any cognitive and behavioural symptoms manifest. Due to its nature, brain reserve can be observed in healthy individuals. A variety of factors, including lifestyle enrichment factors, such as education, general mental stimulation, psychical exercise, leisure activities/choices and occupation attainment are thought to contribute to increased reserves and, as such, would predict more successful cognitive ageing (Cabeza et al., 2018; Darwish, Farran, Assaad, \& Chaaya, 2018; Foubert-Samier et al., 2012; Hötting \& Röder, 2013; Perneczky et al., 2019; Ritchie et al., 2019; Yaffe et al., 2009). Bilingualism can also be considered to be a factor that promotes healthy cognitive ageing by building cognitive and/or brain reserves. Several studies have reported that bilingualism contributes to the delay of the onset of dementia symptoms in neurodegenerative diseases, most commonly in Alzheimer's disease or Mild cognitive impairment (Alladi et al., 2013; Anderson, Hawrylewicz, \& Grundy, 2020; Bialystok, Craik, $\&$ Freedman, 2007). As such, interventions in the form of second language learning have also been suggested to have the potential of slowing down decline associated with older age (Antoniou, Gunasekera, \& Wong, 2013), albeit additional language learning as an indirect intervention has been insofar trialled with mixed results (Berggren, Nilsson, Brehmer, Schmiedek, \& Lövdén, 2020; Bubbico et al., 2019).

If bilingualism has such a strong effect in brain structure, it is worth looking at its effects on brain regions implicated in some prominent dementia symptoms, such as difficulties with episodic memory (Hugo \& Ganguli, 2014). One of such regions is the hippocampus, a grey matter structure located deep in the medial temporal lobe. The hippocampus is subject to atrophy in healthy ageing by annual loss of $0.85 \%$; this rate of atrophy surpasses that of other brain structures and becomes increasingly rapid with older age (Fjell et al., 2009; Fraser, Shaw, $\&$ Cherbuin, 2015). The hippocampus is mostly associated with supporting episodic memory 
function, but it also underlies other important aspects of cognition, such as recognition, spatial processing of cognitive spaces (time and space), language learning, emotional behaviour and mental imagery (Anand \& Dhikav, 2012; Bellmund, Gärdenfors, Moser, \& Doeller, 2018; Bird \& Burgess, 2008; Ullman, 2004). Previous work has linked reductions in hippocampal size with verbal and non-verbal episodic memory performance decline in healthy ageing (Gorbach et al., 2017; O'Shea, Cohen, Porges, Nissim, \& Woods, 2016) and global cognition decline in clinical patients (Bonner-Jackson, Mahmoud, Miller, \& Banks, 2015; Rosselli et al., 2019). These findings expand to a variety of neurodegenerative diseases, such as Parkinson's disease (Brück, Kurki, Kaasinen, Vahlberg, \& Rinne, 2004; Das, Hwang, \& Poston, 2019; Wilson, Niccolini, Pellicano, \& Politis, 2019) and Relapsing-Remitting Multiple Sclerosis (Debernard et al., 2015; Koenig et al., 2014). Moreover, hippocampal atrophy is an established indicator for conversion from healthy ageing process to development of mild cognitive impairment and dementia (Fotuhi, Do, \& Jack, 2012) and smaller hippocampal size is a predictor for an increased risk of and faster conversion from Mild Cognitive Impairment to Alzheimer's Disease (Apostolova et al., 2006). However, the hippocampus has been shown to be plastic and respond to changes in behaviour. For example, behavioural or physical interventions can impact hippocampal volume and improve memory performance in the older age, effectively reversing age-related hippocampal tissue loss (Erickson et al., 2011; Firth et al., 2018; Lövdén et al., 2012). Early life intellectual enrichment has been linked to increased hippocampus (Sumowski et al., 2016) and increased volume of this structure has been shown to contribute to cognitive resilience in clinical ageing brain (Erten-Lyons et al., 2009). In sum, not only the hippocampus appears to be a malleable brain region, but this malleability seems to have correlates in behaviour, and to be particularly affected by external stimulations and/or experiences. In the light of this, it is interesting to look at whether a challenging experience such as bilingualism might have an effect on the structure of the hippocampus, and how these would be expressed in older age.

As already mentioned, the cognitive challenges that bilingualism poses often lead to restructuring of brain regions involved in language acquisition and control (Pliatsikas, 2020). Since the hippocampus is a key structure for processes like vocabulary acquisition (Breitenstein et al., 2005), it is a good candidate structure for structural effects of bilingualism to emerge. Indeed, bilingualism has been shown to affect the shape and size of the hippocampus, at least in healthy adult populations that are active learners and/or users of an additional language. For example Mårtensson et al. (2012) examined Swedish interpreter students and found a 
significant volumetric increase in the right hippocampus following an intensive 3 month language course. Similarly, Bellander et al. (2016) also reported expansion of the right hippocampus in young Swedish speakers as they acquired Italian vocabulary over the course of 4 months; interestingly, expansions were not related to the amount of vocabulary acquired, but to the amount of time spent studying the L2. In a more recent longitudinal study, DeLuca, Rothman, \& Pliatsikas (2019) tested bilinguals living in an immersive L2 environment for three years and reported significant reshaping of the right hippocampus in the form of simultaneous expansions and contractions of different portions of the structure. Since these effects have been reported in younger bilinguals, it could be hypothesised that long-term bilingual experience would lead to brain reserve in the hippocampus, in the form of larger structures in bilinguals versus monolinguals, similar to what has been reported for other brain regions. However, the available evidence remains limited (see Zhang, Wu, \& Thierry, (2020), for a review). For example, Li and colleagues (2017) used a region of interest approach to compare hippocampal volumes between highly proficient bimodal Mandarin Chinese - Chinese Sign Language bilinguals and Mandarin Chinese monolinguals (aged 29-67). They reported enlarged hippocampus for the former group, who also reported to engage in active use of both their languages on a regular basis. However, Olsen and colleagues (2015) failed to report volumetric differences in the hippocampus between 70-year old bilinguals and monolinguals, although they did report differences in other parts of the temporal lobe.

It becomes apparent that the limited available information on how bilingualism affects the hippocampus remains mixed, justifying the need for further studies and different approaches to the issue. One of these approaches concerns how bilingualism itself is operationalised; indeed, the vast majority of the studies looking at the effects of bilingualism in the young and old have treated it as a dichotomous variable and performed straightforward cross-sectional between bilinguals versus monolinguals, an approach that might lead to a significant variability within the bilingual group to be lost. Consequently, there has recently been a push to rather explore the individual differences within bilinguals, expressed by measures such as age of L2 acquisition and language use patterns across a variety of contexts; in other words, an approach that treats bilingualism in a more nuanced way as a continuum by finding ways to quantify the bilingual experience (Bak, 2016b; Bialystok, 2016; Luk \& Bialystok, 2013; De Cat, Gusnanto \& Serratrice, 2018; Gullifer et al., 2018; Beatty-Martínez et al., 2019; DeLuca et al. 2019, 2020). To date, no study has investigated the effects of longterm immersive bilingualism on the brain structure in the older age, while treating bilingualism 
as a spectrum of experiences. As the hippocampus is sensitive to both bilingualism and ageing processes, we examined if the findings in bilingual younger populations can be replicated in older individuals; that is, whether bilingual experience can predict any volumetric changes in this brain structure, and also whether any structural effects would be accompanied by commensurate effects on memory performance.

With the above in mind, the overall aim of this study was to examine the effects of long-term naturalistic immersion in a second language environment on the hippocampus in older healthy populations. Highly proficient speakers of English as a second language and monolingual controls underwent a behavioural and MRI testing battery assessing their memory and hippocampal structure, accompanied by collection of their detailed language background information. The specific aims of the present study were twofold: First, to carry out a crosssectional comparison between the two groups in order to assess the effects of bilingualism on cognition and hippocampal shape and volume. Second, to investigate whether individual differences in language use patterns can further explain variability in cognition and the brain in older age.

In light of previous results, four hypotheses regarding the hippocampal structure and memory performance were raised. First, and in line with previous findings in younger groups, as all participants were cognitively healthy, we expected to see an increased volume of the hippocampus in the bilingual group. Second, we expected bilingual experience, quantified as a bilingualism composite score, to be a significant predictor of hippocampal volumes. Altogether, these effects would indicate a potential neuroprotective effect of bilingualism in the older age, which would relate to the individual experiences of the bilinguals. The third hypothesis related bilingualism to cognitive performance and memory. Specifically, if bilingualism contributes to expansions in the hippocampal volume, better episodic memory performance can be expected in bilinguals. Finally, our fourth hypothesis was that, if the quantified bilingual experiences significantly predict hippocampal volume, a similar effect should be predicted for performance in episodic memory tasks.

\section{Methods}

Participants

Forty-eight healthy older adults (30 females, $m$ Age: 62.19, SD: 9.62, range: 48-84) were recruited for the study. Of these, 23 were bilingual or multilingual speakers of L2 English (16 females, $m$ Age: $58.48, \mathrm{SD}=6.77$, range: $49-73$ ) (henceforth referred to as 'bilinguals') and 
25 were functionally monolingual native English speakers (mAge $=65.60, \mathrm{SD}=10.68$, range: 48-84) (henceforth referred to as 'monolinguals'). All participants were right-handed and reported no neurological disorders or history of speech and language impairments, and they were all residents of the UK at the time of testing. Prior to participation, subjects provided written informed consent and reported no counterindications to MRI scanning. All participants scored within the normal range of the ACE-III cognitive score (Hsieh, Schubert, Hoon, Mioshi, \& Hodges, 2013) suggesting no indications of cognitive impairment.

The bilingual participants spoke a variety of first languages but converged on English being an additional language. Most of these participants $(\mathrm{N}=22)$ reported speaking an additional language or languages to English and their respective L1. In terms of language proficiency, two individuals reported English to be their most proficient language, 16 reported English as their second most proficient language, 3 individuals reported English as their third most proficient language, and one reported English as their fourth most proficient language. These participants usually acquired English at school age (mAoA: 10.65; SD: 6.12; range: 030). The majority of this group were born outside the UK and had moved to the UK at various ages. Two participants in this group were born in the UK but did not speak English at home and started learning English upon commencement of formal education. One participant was born in the Netherlands and reported growing up in a bilingual Dutch/English household. Three participants reported English as their most proficient language at the time of testing. Participants in this group had been immersed in their second language environment for an extended period of time (mean length of residence in the $\mathrm{UK}=29.52$ years; $\mathrm{SD}=17.20$; range 1-60) and were using English for everyday communication and were competent and highly proficient users of this language (see Table 2).

Of the monolingual group, 13 participants reported some exposure to an additional language, usually at school age. However, none of the monolinguals reported continuous engagement with their additional languages at the present day, mostly advising 'occasional use while on holiday'. Active engagement with their L2 was normally in a classroom setting during adolescence that was decades prior to testing. Language and Social Background Questionnaire (see below) suggests bilingualism composite scores under -3.12 as firmly bilingual and scores over 1.22 as firmly monolingual. Individuals scoring between these values lie in a 'grey area', with ambiguous language background. Only two participants in this group did not score firmly in the 'monolingual' category, as defined by the LSBQ; one of these participants had no working knowledge of any other languages but reported growing up in an environment where he was surrounded by other languages. The other participant had extensive experience with 
French, although they were not actively engaging in use of French in their everyday life. Therefore, these two participants were not excluded from the 'monolingual' group. No participants were excluded from analysis based on their linguistic background. For full language and demographic information, see Table 1.

\section{(Tables 1 - 3 approximately here)}

\section{Data collection}

Behavioural testing and MRI scanning sessions were mostly conducted on the same day, although in some cases, where it was not feasible to conduct all aspects of testing in one day, participants returned for a second round of testing at a later date. The maximum time period between the testing sessions was 3 months.

\section{Behavioural data collection}

\section{Language and Social Background Questionnaire (LSBQ)}

The participants completed the language and social background questionnaire (LSBQ) (Anderson, Mak, Keyvani Chahi, \& Bialystok, 2018). The LSBQ is a questionnaire that allows to collect detailed information about one's social (professional attainment, country of birth, etc.) and linguistic background (spoken languages, self-rated proficiency, age and context of acquisition), and the extent of language use across different contexts. Bilingual experience is quantified via a bilingualism composite score (BCS) as a sum of various quantitative experience-based factors such as extent of L2 use in home and social settings (DeLuca, Rothman, Bialystok, et al., 2019; DeLuca et al., 2020). The BCS allows for measurement and treatment of bilingualism as a continuous variable, as opposed to more commonly used stratification of participants in monolingual and bilingual language groups (de Bruin, 2019; Pliatsikas, DeLuca, \& Voits, 2020; Surrain \& Luk, 2019).

The participants were asked to complete a paper copy of the LSBQ on their own, but an examiner was present to answer any questions participants may have and provide clarification, if needed. As LSBQ presumes English to be the native or first language by default, the calculations using the factor score calculator were canonical for the native English speakers, whereas the calculations for those with other first languages were altered for their native language to be treated as the baseline, and English regarded as L2. This required inversion of some scores from the questionnaire upon input in the calculator (as in DeLuca, Rothman, Bialystok, et al., 2019). 


\section{NIH Toolbox}

A modified cognition battery of the NIH Toolbox (Weintraub et al., 2013) was used to assess the cognitive functioning of the study participants. The NIH toolbox is an iPad-based testing battery. For the present study in particular, two tests were of interest: the NIH-TB Picture Sequence Memory Test (testing episodic memory performance) and NIH-TB List Sorting Test (testing working memory performance). Hippocampus is typically associated with episodic memory performance, while working memory relies on frontal and parietal networks (Nee \& D'Esposito, 2015). Nonetheless, hippocampal volume has been shown to correlate with performance in the specific NIH toolbox working memory task in ageing populations (O'Shea et al., 2016). Inclusion of two tasks tapping into different types of memory allows to test the specificity of the results to cognitive function with the hippocampus and for involvement of this structure in working memory processes. In the List Sorting Working Memory Test participants were presented with cartoon pictures of different foods and animals, with accompanying audio presentation and written text naming the item. The participants were then asked to say the items back to the examiner listing them in size order from the smallest to the biggest. In the first condition, participants are asked to recall stimuli from one category. In the second condition, participants are presented with stimuli from two categories (foods and animals) in mixed order and have to recall the items in size order for each category separately. The number of items in each trial increases until two trials of the same length are failed. All items were of high frequency, easily recognisable and unambiguous. Test is scored as the total items correct across all trials.

In the Picture Sequence Memory Test sequences of pictured objects and activities were presented in a particular order. The participants were then asked to reproduce the same order on the screen. The pictures are presented in two trials: one with a 15-step sequence and the other with an 18-step sequence. The second sequence is a repetition of the same 15 items, with 3 novel items added in the middle of the sequence. The score is derived by the cumulative number of adjacent pairs remembered correctly over the learning trials.

Both NIH toolbox tests were automatically scored with three types of scores: uncorrected standard scores (normative mean $=100, \mathrm{SD}=15$ ), age-corrected standard scores, and fully corrected T-Scores, which account for age and other demographic characteristics the demographic information is submitted prior to behavioural testing. For this study uncorrected standard scores were used to measure behavioural performance; moreover, age 
and education measures, also collected as part of the behavioural data via the NIH toolbox, were included in the analysis as covariates.

\section{Addenbrooke's Cognitive Examination (ACE-III)}

Participants were asked to complete the Addenbrooke's Cognitive Examination (ACEIII) testing battery (Hsieh et al., 2013). ACE-III is a widely used screening tool for cognitive deficits in Alzheimer's Disease and Frontotemporal Dementia. It is scored out of 100 and covers five cognitive domains - attention, memory, fluency, language, and visuospatial processing, where an overall score of less than 82 suggests dementia. The domain of primary interest in this study was memory. The tasks tapping into memory are scattered throughout the exam and tap into working and semantic memory. More specifically, the participants are asked to recall previously repeated words, memorise and recall a fictional name and address, and recall well-known historically significant people (Bruno \& Vignaga, 2019). The memory domain is scored out of 26. The score provides a baseline information of one's composite memory performance and were used in addition to NIH toolbox cognitive battery episodic and working memory tasks.

\section{MRI data acquisition}

For the purpose of structural brain analysis, high resolution $\mathrm{T} 1$ anatomical scans were acquired using a MPRAGE sequence on a 3T Siemens MAGNETOM Prisma_fit MRI scanner, with a 32-channel Head Matrix coil and Syngo software (256 sagittal slices, $0.7 \mathrm{~mm}$ slice thickness, in-plane resolution $250 \times 250$, acquisition matrix of $246 \times 256 \mathrm{~mm}, 224 \mathrm{~mm}$ FoV, $\mathrm{TR}=2400 \mathrm{~ms}, \mathrm{TE}=2.41 \mathrm{~ms}$, inversion time $=1140 \mathrm{~ms}$, flip angle $=8^{\circ}$ ). The scan lasted approximately 10 minutes.

\section{MRI data processing}

\section{Preprocessing}

Structural neuroimaging data were pre-processed and analysed with software pipelines in FSL. The raw neuroimaging data were converted from dicom to nifti file format and stored in a BIDS structure format using pyBIDSconv1.1.7. (Lindner, 2018). All T1-weighted scans were then anatomically pre-processed using the fsl_anat pipeline in FSL 5.0.9 (Smith et al., 2004). This involves a standard use of various MRI processing tools including the brain 
extraction tool (BET) used for skull stripping the raw T1 images and bias field correction as part of the pipeline. Bias field corrected T1 images were used for segmentation of the hippocampus. The brain extractions were manually checked for quality control. This revealed that five participants had unsatisfactory extraction, and this was addressed by applying custom extraction parameters and rerunning BET until we yielded satisfactory skull-stripped brain extractions.

\section{Volume}

Segmentation of the bilateral hippocampus was performed using FIRST, a toolbox of FSL. FIRST performs registration, segmentation based on Bayesian appearance and boundary corrections to produce segmented subcortical structures (Patenaude, Smith, Kennedy, \& Jenkinson, 2011). Hippocampal extractions were verified visually and were not deemed satisfactory for one participant. While all other segmentations were performed on biascorrected full T1 images, for the unsatisfactory segmentation, the pipeline was run again on the brain-extracted image, which produced a satisfactory subcortical segmentation of the structure. Hippocampal raw volumes were calculated using fslstats. Hippocampal volume was normalised by dividing it by total brain volume as estimated from the skull stripped image.

As FIRST provides two volumetric values - one for the left hippocampus, and one for the right - we initially ran a linear fixed effects model including a main effect of Language group (i.e., monolingual vs. bilingual), Hemisphere (i.e., left vs right) and the interaction between the two as predictors of hippocampal volume.

Subsequently, we used a hierarchical regression to investigate whether degree of bilingualism predicts hippocampal volume beyond other demographic factors and memory performance. To do so, we used demographic measures, individual test scores from the NIH toolbox and ACE-III and the LSBQ scores to build and compare several linear fixed effects models in an increasing order of complexity. The models were built and executed in $\mathrm{R}$ version 4.0.0. All continuous predictors of hippocampus volume (age, education, length of immersion, L2 Home, L2 social, BCS, List Sorting Working Memory Test scores, Picture Sequence Memory Test scores, ACE-III memory domain scores) were mean-centred ${ }^{1}$. The normalised hippocampal volumes were normally distributed in this participant sample $(\mathrm{W}=0.989, \mathrm{p}$ $=0.586)$.

\footnotetext{
${ }^{1}$ Given the age of our participants, we did not use age of acquisition as a reliable predictor because many bilingual individuals reported learning English at school, which does not accurately portray the actual engagement in English use across the lifespan and at the time of testing.
} 
The initial model (Model 1) explains hippocampus volume as a function of age, education, and hemisphere. The second model (Model 2) adds memory performance measures as the independent variables to the model. The decision to include memory performance measures as predictors in this model (whereas, more typically one would see brain measures as predictors for behaviour) was done to account for the individual variance in the hippocampal volume which has been shown to account for behavioural performance in other studies. In other words, like the demographical variables, memory performance is effectively acting as a predictor of no interest. The third model (Model 3) introduces our main predictor of interest, the LSBQ BCS ${ }^{2}$.

\section{Shape}

As part of the FIRST pipeline, vertex analysis was also performed on the bilateral hippocampus to establish if BCS is a predictor for changes in the hippocampal shape. The standard procedure was implemented in FIRST, by which each structure was linearly registered (using 6 degrees of freedom) to the sample-specific average surface and mapped in MNI space. Analysis was carried out using the Randomise pipeline in FSL, in which permutation-based non-parametric analysis, with 10000 permutations for each factor of interest testing were ran and corrected for multiple comparisons using threshold-free cluster enhancement (Smith \& Nichols, 2009). The correlational design matrix contained the factor of interest, BCS, and covariates of age and education. This resulted in spatial maps showing local contractions and expansions of the structure (i.e., perpendicular displacement from the study-specific template average surface) of interest as a function of bilingualism, thresholded at $\mathrm{p}=<0.05$.

The participant with unsatisfactory hippocampal segmentations from the complete T1 scan had to be excluded from shape analysis as it could not be included in the generation of the study-specific template of the hippocampus. Therefore, the study-specific template of the hippocampal vertices for the shape analysis was created without this participant. Note that the manual extraction of the hippocampal volume from the brain-extracted image was successful for this participant, meaning there is a discrepancy in the number of data points between the volumetric and shape analyses.

\footnotetext{
${ }^{2}$ A version of Model 3 was also envisaged with L2 home and L2 social use scores as measures of bilingualism, and the interaction of two, instead of the LSBQ composite score. However, as these scores heavily contribute to the LSBQ composite score (L2 Home and L2 Social scores have 33\% and 30\% weighting in the BCS calculation), and they were highly correlated between them ( $\operatorname{cor}=0.95 ; \mathrm{p}<0.001)$, it was deemed inappropriate to include these scores as separate predictors in the same model as they introduce significant multicollinearity issues
} 


\section{Behavioural analysis}

Pertaining to the third and fourth hypotheses, we aimed to explore if bilingualism as a continuous variable and also as a group variable predicts memory performance when other variables, including hippocampal volume, are accounted for. The models were built in a similar manner to the volumetric analysis models of the hippocampus. For this analysis, hippocampal volumes were summed across hemispheres and the total hippocampal volume was used as a predictor for memory performance.

First, we ran models to examine whether the two groups performed differently on behavioural tasks, with age included as a nuisance covariate. Then, BCS was examined as a predictor for performance in individual memory tasks, controlled for age, education, and total hippocampal volume. This included running separate models for all three memory performance measures - NIH toolbox episodic memory score, NIH toolbox working memory score and ACE-III memory score. In Model 4 each memory measure as a dependent variable was predicted by age and education as independent variables. In the following step, Model 5, total hippocampal volume was added to the list of independent variables. Finally, LSBQ BCS was added as an independent predictor in Model 6. All continuous variables were mean-centred.

\section{Results}

\section{Neuroimaging results}

\section{Volume}

Our between-groups comparison revealed a significant main effect of bilingualism on the hippocampus volume $(\mathrm{p}<0.05)$, where non-native speakers of English exhibiter larger hippocampal volume. There was no significant main effect of hemisphere $(p=0.82)$, nor a significant hemisphere by language group interaction $(\mathrm{p}=0.66)$ (see Fig. 1$)$. This result suggests that overall bilingual individuals have increased hippocampal volume bilaterally.

The next set of analyses (see Table 4) used hierarchical regression models to investigate whether the observed increased hippocampal volumes can be predicted by the amount of bilingual experience. Results from Model 1 revealed a significant negative effect of age, such that with increasing age the observed hippocampus volumes became smaller, and a significant positive effect of education where higher educational attainment predicts higher hippocampal volume. No significant effects of hemisphere were observed. 
Results from Model 2 revealed that age and education remained significant contributors to the hippocampal volume, whereas hemisphere was not. Moreover, overall composite memory performance, measured by the memory subdomain of ACE-III, correlated positively with hippocampal volume, whereas performance in the episodic memory task of the NIH toolbox correlated negatively, and performance in the working memory task of the NIH toolbox was not significantly associated with hippocampal volume

Finally, Model 3 revealed that, while the effects of age, education, and episodic memory performance remained significant, BCS also emerged as a highly significant unique contributor to the hippocampal volume, with higher BCS being positively associated with hippocampal volume (see Fig. 2).

Akaike Information Criterion (AIC) was established for all models to determine the goodness of fit and choose the most appropriate model for the data. The lowest AIC, indicating the best model fit for the data was for the most complex model (Model 3).

(Table 4 and Figures 1-2 approximately here)

\section{Shape}

Vertex analysis revealed no significant local expansions or contractions of the bilateral hippocampus as a function of BCS.

\section{Behavioural results}

Group performance in the three memory tasks is illustrated in Figures 3-5. No significant between-groups differences emerged for any of the memory scores, although there was a trend for bilinguals to perform better in the ACE-III memory domain $(p=0.054)$. However, it is difficult to interpret these results due to the near ceiling effect in ACE-III (see Fig. 3) - this was to be expected due to the nature of the test, which is to act as a dementia screening tool.

\section{(Figures 3-5 approximately here)}

In the hierarchical regressions relating BCS as a continuous measure of bilingualism the results were as follows. For the NIH toolbox working memory task hierarchical regressions showed that none of the predictors (age, education, total hippocampal volume, BCS) significantly explained working memory performance (see Table 5). 
For the NIH toolbox episodic memory task, age was a significant predictor in the Model 4 and remained a significant predictor in Models 5 and 6, so that with increased age episodic memory performance is subject to decline. Education was a significant positive predictor in Models 5 and 6. Hippocampal volume also predicted episodic memory performance in Model 6 , however, the relationship was negative. In Model 6, BCS did not significantly contribute to episodic memory performance. From all three models Model 6 was also the best fit for data with an adjusted $\mathrm{R}^{2}$ of 0.239 and the lowest Akaike Information Criterion indicating the best fit (see table 6).

For the ACE-III cognition battery memory domain, across all three models no independent variables significantly predicted composite memory performance, apart from a trend for BCS in Model $6(\mathrm{p}=0.064)$, suggesting that higher BCS might predict better performance in the ACE-III memory domain (see table 7).

Unlike the models explaining the volumetric variation of the hippocampus as a result of demographic variables, memory performance, and bilingualism, these linear regression models explaining the variance in memory performance were not a good fit for the data. In all cases, model comparison revealed the increasingly complex models not to improve their explanatory power over the data. The only exception to this were models explaining NIH episodic memory scores as a function of the above described IVs, where most complex model offered a marginal improvement over the simpler models $(p=0.059)$. Therefore, only the episodic memory performance can be measured as a function of age, education, hippocampal volume, and bilingualism. See hierarchical regression model comparison for all three memory scores in tables 5-7.

\section{(Tables 5-7 approximately here)}

\section{Discussion}

In the present study we examined the effects bilingualism might have on the ageing brain with a particular focus on the hippocampus and related cognitive abilities. The hippocampus is a structure subject to volumetric decline with ageing (Fjell et al., 2009). Bilingualism on the other hand has been shown to reinforce the structure of a variety of brain regions, including the hippocampus (Pliatsikas, 2020), an effect that could bolster neural and cognitive reserves in the older age (Perani \& Abutalebi, 2015), processes that have direct implications in variability of ageing trajectories (Anderson et al., 2020). This is of particular 
importance with respect to the hippocampus, because any reinforcement of this structure might have important implications for memory abilities in older age, but also in the timing for conversion from healthy ageing to dementia (Fotuhi et al., 2012). Indeed, the hippocampus has been shown to change in shape and increase in volume following intensive, immersive language experiences, particularly in young adult populations (DeLuca, Rothman, \& Pliatsikas, 2019; Li et al., 2017; Mårtensson et al., 2012).

Our results corroborate those of previous studies and extend them to older populations that are immersed in bilingual environments (but see Olsen et al., 2015). Specifically, longterm immersive engagement in our sample was revealed to have a significant positive effect on the bilateral hippocampal volume when compared to a monolingual control group. Moreover, through quantification of bilingualism and treatment of this factor as a continuum, we showed that greater engagement in second language use predicts increased hippocampal volumes. However, these volumetric differences did not translate into significant effects on the hippocampal shape; this effect is harder to interpret, but it also challenges the relationship between volume and shape as they are assessed by out tools- besides, the few available studies have, similarly to ours, typically reported effects on one metric only, not both (DeLuca, Rothman, \& Pliatsikas, 2019; Li et al., 2017; Mårtensson et al., 2012). Moreover, episodic and working memory performance of our samples was also tested with three different tasks, but bilingualism was not shown to be a significant predictor on behavioural performance. The remainder of this section will discuss our structural findings against theoretical suggestions for the effects of the bilingualism on the brain, followed by a discussion on the apparent mismatch between structural and behavioural findings, and the relevant implications for cognitive ageing and bilingualism.

Our findings on hippocampal structure are in line with the hypothesis that continuous engagement with an additional language would present structural reinforcement of the brain (Borsa et al., 2018; Pliatsikas, Moschopoulou, \& Saddy, 2017). Similar effects are not uncommon among studies looking at brain structure in bilingualism; indeed, there is a lot of evidence that the cognitively challenging experience of acquiring and controlling two languages leads to structural adaptations of implicated areas with the aim of achieving maximum efficiency (Hayakawa \& Marian, 2019); notably these adaptations have been suggested to be dynamic in nature, with temporal tissue increases being followed by return to baseline volume but with more resilient local connections, which in turn that could be more resistant to age-related decline (Pliatsikas, 2020). Based on this, our findings can have one of two possible but interrelated explanations: first, that the observed difference reflects a 
volumetric increase for bilinguals, similar to what has been claimed for such findings in younger bilinguals; second, this perceived increase could actually signify slower age-related decline of the hippocampus for bilinguals when compared to monolinguals, therefore providing evidence that bilingualism boosts resilience against age-related deterioration of the hippocampus, what has also been characterised as a brain reserve (Stern et al., 2018). The particular age range of our participants, who are young enough to be cognitively healthy, but potentially on the cusp of the symptoms of cognitive and brain decline to emerge, does not allow us to differentiate between the two mechanisms, which remain equally plausible, and might even feed each other; nevertheless, evidence form this exact pivotal point in cognitive ageing might prove useful in explaining effects in later life in bilinguals, including the mechanism behind the emergence of MCI and its conversion to dementia (Berkes, Bialystok, Craik, Troyer, \& Freedman, 2020; Costumero et al., 2020; Duncan et al., 2018). Notably, the finding that the bilingual experience can affect the hippocampus structurally follows from similar findings in younger bilinguals (DeLuca, Rothman, \& Pliatsikas, 2019), but most importantly it constitutes the first piece of evidence that brain reserves in older bilinguals are modulated by the bilingual experience.

Finally, we also looked what effects bilingualism might have on the performance in cognitive domains typically associated with the hippocampus - most notably, episodic memory. With the potential effects of demographic factors, such as age and educational attainment, and hippocampal volume all accounted for, bilingualism did not emerge as a significant predictor for memory performance across any of the three tests we administered.

This pattern of results calls for an explanation for the apparent discrepancy between the effects of bilingualism on brain structure and cognitive performance. Recall that the average age of our participants is 62 years, which, as already mentioned, puts them on the 'younger' end of the ageing spectrum. While some ageing processes may have already begun, these participants are still cognitively healthy individuals with no signs of memory impairment, which is also attested by the near-ceiling score of both groups in the ACE-III memory domain. Nevertheless, our structural findings indicate that the processes that underlie the building of a brain reserve in bilinguals are already in action, but without measurable equivalents in behaviour. This pattern is reminiscent of recent evidence suggesting that the mapping of behaviour to brain function is also not straightforward, at least in healthy populations (DeLuca et al., 2020), and further suggests that studying task performance alone might not be sufficient to assess the effects of bilingualism on the brain. 
Our findings call for further and more focused investigations on the effects of bilingualism on the ageing brain, and in particular on age ranges similar to ours, where the first signs of cognitive decline might emerge. Moreover, longitudinal designs would allow to further examine the underlying mechanisms in more detail, including their onset and trajectory, as well as the factors they may interact with. Importantly, such designs should not just account for bilingualism as a categorical variable, but also look at the extent of it, based on linguistic experiences and patterns of language use. Examining bilingualism as a continuous variable allows to account for within groups variability which may be lost in a more classically defined monolingual vs bilingual groups comparison (Leivada, Westergaard, Duñabeitia, \& Rothman, 2020; Luk \& Bialystok, 2013; Surrain \& Luk, 2019). Moreover, focused studies similar to this one, are required with clinical populations too, to add to a small but growing literature that will help us better understand the potential clinical implications both in healthy and pathological ageing (Voits, Pliatsikas, Robson, \& Rothman, 2019).

To conclude, the results of this study contribute to the literature examining the effects of bilingualism on ageing; specifically, we have shown greater volume of the hippocampus on bilinguals vs monolinguals, which is also predicted by the amount of bilingual experiences; these findings were not accompanied by comparable effects of bilingualism in episodic memory performance. These findings shed further light on how speaking more than one language may contribute to building up of a brain reserve in the older age. Moreover, the results of this study further our understanding on the effects immersive, long-term bilingualism confer to the brain structure and memory performance in the later years of life. 


\section{References}

Alladi, S., Bak, T. H., Duggirala, V., Surampudi, B., Shailaja, M., Shukla, A. K., ... Kaul, S. (2013). Bilingualism delays age at onset of dementia, indipendent of education and immigration status. Neurology, 81, 1938-1944.

https://doi.org/10.1212/01.WNL.0000437347.92583.fc

Anand, K., \& Dhikav, V. (2012). Hippocampus in health and disease: An overview. Annals of Indian Academy of Neurology, 15(4), 239-246. https://doi.org/10.4103/09722327.104323

Anderson, J. A. E., Grundy, J. G., De Frutos, J., Barker, R. M., Grady, C., \& Bialystok, E. (2018). Effects of bilingualism on white matter integrity in older adults. NeuroImage, 167(June 2017), 143-150. https://doi.org/10.1016/j.neuroimage.2017.11.038

Anderson, J. A. E., Hawrylewicz, K., \& Grundy, J. G. (2020). Does bilingualism protect against dementia? A meta-analysis. Psychonomic Bulletin \& Review. https://doi.org/10.3758/s13423-020-01736-5

Anderson, J. A. E., Mak, L., Keyvani Chahi, A., \& Bialystok, E. (2018). The language and social background questionnaire: Assessing degree of bilingualism in a diverse population. Behavior Research Methods, 50(1), 250-263. https://doi.org/10.3758/s13428-017-0867-9

Antoniou, M., Gunasekera, G. M., \& Wong, P. C. M. (2013). Foreign language training as cognitive therapy for age-related cognitive decline: A hypothesis for future research. Neuroscience \& Biobehavioral Reviews, 37(10), 2689-2698. https://doi.org/10.1016/j.neubiorev.2013.09.004

Apostolova, L. G., Dutton, R. A., Dinov, I. D., Hayashi, K. M., Toga, A. W., Cummings, J. L., \& Thompson, P. M. (2006). Conversion of mild cognitive impairment to alzheimer disease predicted by hippocampal atrophy maps. Archives of Neurology, 63(5), 693699. https://doi.org/10.1001/archneur.63.5.693

Bellander, M., Berggren, R., Mårtensson, J., Brehmer, Y., Wenger, E., Li, T. Q., ... Lövdén, M. (2016). Behavioral correlates of changes in hippocampal gray matter structure during acquisition of foreign vocabulary. NeuroImage, 131, 205-213. https://doi.org/10.1016/j.neuroimage.2015.10.020

Bellmund, J. L. S., Gärdenfors, P., Moser, E. I., \& Doeller, C. F. (2018). Navigating cognition: Spatial codes for human thinking. Science (New York, N.Y.), 362(6415). https://doi.org/10.1126/science.aat6766

Berggren, R., Nilsson, J., Brehmer, Y., Schmiedek, F., \& Lövdén, M. (2020). Foreign language learning in older age does not improve memory or intelligence: Evidence from a randomized controlled study. Psychology and Aging, 35(2), 212-219. https://doi.org/10.1037/pag0000439

Berkes, M., Bialystok, E., Craik, F. I. M., Troyer, A., \& Freedman, M. (2020). Conversion of Mild Cognitive Impairment to Alzheimer Disease in Monolingual and Bilingual Patients. Alzheimer Disease and Associated Disorders, 00(00), 1-6. https://doi.org/10.1097/WAD.0000000000000373

Bettio, L. E. B., Rajendran, L., \& Gil-Mohapel, J. (2017). The effects of aging in the hippocampus and cognitive decline. Neuroscience and Biobehavioral Reviews, 79(November 2016), 66-86. https://doi.org/10.1016/j.neubiorev.2017.04.030

Bialystok, E., Craik, F. I. M., \& Freedman, M. (2007). Bilingualism as a protection against the onset of symptoms of dementia. Neuropsychologia, 45(2), 459-464. https://doi.org/10.1016/j.neuropsychologia.2006.10.009

Bialystok, E., Craik, F. I. M., Klein, R., \& Viswanathan, M. (2004). Bilingualism, Aging, and Cognitive Control: Evidence From the Simon Task. Psychology and Aging, 19(2), 290303. https://doi.org/10.1037/0882-7974.19.2.290 
Bialystok, E., Craik, F., \& Luk, G. (2008). Cognitive Control and Lexical Access in Younger and Older Bilinguals. Journal of Experimental Psychology: Learning Memory and Cognition, 34(4), 859-873. https://doi.org/10.1037/0278-7393.34.4.859

Bird, C. M., \& Burgess, N. (2008). The hippocampus and memory: Insights from spatial processing. Nature Reviews Neuroscience, 9(3), 182-194. https://doi.org/10.1038/nrn2335

Bonner-Jackson, A., Mahmoud, S., Miller, J., \& Banks, S. J. (2015). Verbal and non-verbal memory and hippocampal volumes in a memory clinic population. Alzheimer's Research and Therapy, 7(1), 1-10. https://doi.org/10.1186/s13195-015-0147-9

Borsa, V. M., Perani, D., Della Rosa, P. A., Videsott, G., Guidi, L., Weekes, B. S., ... Abutalebi, J. (2018). Bilingualism and healthy aging: Aging effects and neural maintenance. Neuropsychologia, 111(January), 51-61. https://doi.org/10.1016/j.neuropsychologia.2018.01.012

Breitenstein, C., Jansen, A., Deppe, M., Foerster, A. F., Sommer, J., Wolbers, T., \& Knecht, S. (2005). Hippocampus activity differentiates good from poor learners of a novel lexicon. NeuroImage, 25(3), 958-968. https://doi.org/10.1016/j.neuroimage.2004.12.019

Brück, A., Kurki, T., Kaasinen, V., Vahlberg, T., \& Rinne, J. O. (2004). Hippocampal and prefrontal atrophy in patients with early non-demented Parkinson's disease is related to cognitive impairment. Journal of Neurology, Neurosurgery and Psychiatry, 75(10), 1467-1469. https://doi.org/10.1136/jnnp.2003.031237

Bruno, D., \& Vignaga, S. S. (2019). Addenbrooke's cognitive examination III in the diagnosis of dementia: A critical review. Neuropsychiatric Disease and Treatment, 15, 441-447. https://doi.org/10.2147/NDT.S151253

Bubbico, G., Chiacchiaretta, P., Parenti, M., di Marco, M., Panara, V., Sepede, G., ... Perrucci, M. G. (2019). Effects of Second Language Learning on the Plastic Aging Brain: Functional Connectivity, Cognitive Decline, and Reorganization. Frontiers in Neuroscience, 13(May), 1-13. https://doi.org/10.3389/fnins.2019.00423

Cabeza, R., Albert, M., Belleville, S., Craik, F. I. M. M., Duarte, A., Grady, C. L., ... Rajah, M. N. (2018). Maintenance, reserve and compensation: the cognitive neuroscience of healthy ageing. Nature Reviews Neuroscience, 19(11), 701-710. https://doi.org/10.1038/s41583-018-0068-2

Costumero, V., Marin-Marin, L., Calabria, M., Belloch, V., Escudero, J., Baquero, M., ... Ávila, C. (2020). A cross-sectional and longitudinal study on the protective effect of bilingualism against dementia using brain atrophy and cognitive measures. Alzheimer's Research \& Therapy, 12(1), 11. https://doi.org/10.1186/s13195-020-0581-1

Darwish, H., Farran, N., Assaad, S., \& Chaaya, M. (2018). Cognitive reserve factors in a developing country: Education and occupational attainment lower the risk of dementia in a sample of lebanese older adults. Frontiers in Aging Neuroscience, 10(SEP), 1-10. https://doi.org/10.3389/fnagi.2018.00277

Das, T., Hwang, J. J., \& Poston, K. L. (2019). Episodic recognition memory and the hippocampus in Parkinson's disease: A review. Cortex, 113, 191-209. https://doi.org/10.1016/j.cortex.2018.11.021

de Bruin, A. (2019). Not All Bilinguals Are the Same: A Call for More Detailed Assessments and Descriptions of Bilingual Experiences. Behavioral Sciences, 9(3), 1-13. https://doi.org/10.3390/BS9030033

Debernard, L., Melzer, T. R., Alla, S., Eagle, J., Van Stockum, S., Graham, C., ... Mason, D. F. (2015). Deep grey matter MRI abnormalities and cognitive function in relapsingremitting multiple sclerosis. Psychiatry Research - Neuroimaging, 234(3), 352-361. https://doi.org/10.1016/j.pscychresns.2015.10.004

DeLuca, V., Rothman, J., Bialystok, E., \& Pliatsikas, C. (2019). Redefining bilingualism as a 
spectrum of experiences that differentially affects brain structure and function. Proceedings of the National Academy of Sciences, 116(15), 7565-7574. https://doi.org/10.1073/pnas.1811513116

DeLuca, V., Rothman, J., Bialystok, E., \& Pliatsikas, C. (2020). Duration and extent of bilingual experience modulate neurocognitive outcomes. NeuroImage, 204(May 2019), 116222. https://doi.org/10.1016/j.neuroimage.2019.116222

DeLuca, V., Rothman, J., \& Pliatsikas, C. (2019). Linguistic immersion and structural effects on the bilingual brain: a longitudinal study. Bilingualism: Language and Cognition, 22(5), 1160-1175. https://doi.org/10.1017/S1366728918000883

Duncan, H. D., Nikelski, J., Pilon, R., Steffener, J., Chertkow, H., \& Phillips, N. A. (2018). Structural brain differences between monolingual and multilingual patients with mild cognitive impairment and Alzheimer disease: Evidence for cognitive reserve. Neuropsychologia, 109(October 2017), 270-282. https://doi.org/10.1016/j.neuropsychologia.2017.12.036

Erickson, K. I., Voss, M. W., Prakash, R. S., Basak, C., Szabo, A., Chaddock, L., ... Kramer, A. F. (2011). Exercise training increases size of hippocampus and improves memory. Proceedings of the National Academy of Sciences of the United States of America, 108(7), 3017-3022. https://doi.org/10.1073/pnas.1015950108

Erten-Lyons, D., Woltjer, R. L., Dodge, H., Nixon, R., Vorobik, R., Calvert, J. F., ... Kaye, J. (2009). Factors associated with resistance to dementia despite high Alzheimer disease pathology. Neurology, 72(4), 354-360. https://doi.org/10.1212/01.wnl.0000341273.18141.64

Farokhian, F., Yang, C., Beheshti, I., Matsuda, H., \& Wu, S. (2017). Age-related gray and white matter changes in normal adult brains. Aging and Disease, 8(6), 899-909. https://doi.org/10.14336/AD.2017.0502

Firth, J., Stubbs, B., Vancampfort, D., Schuch, F., Lagopoulos, J., Rosenbaum, S., \& Ward, P. B. (2018). Effect of aerobic exercise on hippocampal volume in humans: A systematic review and meta-analysis. NeuroImage, 166(April 2017), 230-238. https://doi.org/10.1016/j.neuroimage.2017.11.007

Fjell, A. M., Walhovd, K. B., Fennema-Notestine, C., McEvoy, L. K., Hagler, D. J., Holland, D., ... Dale, A. M. (2009). One-year brain atrophy evident in healthy aging. Journal of Neuroscience, 29(48), 15223-15231. https://doi.org/10.1523/JNEUROSCI.325209.2009

Fotuhi, M., Do, D., \& Jack, C. (2012). Modifiable factors that alter the size of the hippocampus with ageing. Nature Reviews Neurology, 8(4), 189-202. https://doi.org/10.1038/nrneurol.2012.27

Foubert-Samier, A., Catheline, G., Amieva, H., Dilharreguy, B., Helmer, C., Allard, M., \& Dartigues, J. F. (2012). Education, occupation, leisure activities, and brain reserve: A population-based study. Neurobiology of Aging, 33(2), 423.e15-423.e25. https://doi.org/10.1016/j.neurobiolaging.2010.09.023

Fraser, M. A., Shaw, M. E., \& Cherbuin, N. (2015). A systematic review and meta-analysis of longitudinal hippocampal atrophy in healthy human ageing. NeuroImage, 112, 364 374. https://doi.org/10.1016/j.neuroimage.2015.03.035

Giorgio, A., Santelli, L., Tomassini, V., Bosnell, R., Smith, S., De Stefano, N., \& JohansenBerg, H. (2010). Age-related changes in grey and white matter structure throughout adulthood. NeuroImage, 51(3), 943-951. https://doi.org/10.1016/j.neuroimage.2010.03.004

Gold, B. T., Kim, C., Johnson, N. F., Kryscio, R. J., \& Smith, C. D. (2013). Lifelong Bilingualism Maintains Neural Efficiency for Cognitive Control in Aging. Journal of Neuroscience, 33(2), 387-396. https://doi.org/10.1523/jneurosci.3837-12.2013 
Gorbach, T., Pudas, S., Lundquist, A., Orädd, G., Josefsson, M., Salami, A., ... Nyberg, L. (2017). Longitudinal association between hippocampus atrophy and episodic-memory decline. Neurobiology of Aging, 51, 167-176. https://doi.org/10.1016/j.neurobiolaging.2016.12.002

Hayakawa, S., \& Marian, V. (2019). Consequences of multilingualism for neural architecture. Behavioral and Brain Functions, 15(1), 1-24. https://doi.org/10.1186/s12993-019-0157-z

Hötting, K., \& Röder, B. (2013). Beneficial effects of physical exercise on neuroplasticity and cognition. Neuroscience and Biobehavioral Reviews, 37(9), 2243-2257. https://doi.org/10.1016/j.neubiorev.2013.04.005

Hsieh, S., Schubert, S., Hoon, C., Mioshi, E., \& Hodges, J. R. (2013). Validation of the Addenbrooke's Cognitive Examination III in Frontotemporal Dementia and Alzheimer's Disease. Dementia and Geriatric Cognitive Disorders, 36(3-4), 242-250. https://doi.org/10.1159/000351671

Hugo, J., \& Ganguli, M. (2014). Dementia and Cognitive Impairment. Clinics in Geriatric Medicine, 30(3), 421-442. https://doi.org/10.1016/j.cger.2014.04.001

Koenig, K. A., Sakaie, K. E., Lowe, M. J., Lin, J., Stone, L., Bermel, R. A., ... Phillips, M. D. (2014). Hippocampal volume is related to cognitive decline and fornicial diffusion measures in multiple sclerosis. Magnetic Resonance Imaging, 32(4), 354-358. https://doi.org/10.1016/j.mri.2013.12.012

Leivada, E., Westergaard, M., Duñabeitia, J. A., \& Rothman, J. (2020). On the phantom-like appearance of bilingualism effects on neurocognition: (How) should we proceed? Bilingualism: Language and Cognition, (May), 1-14. https://doi.org/10.1017/S1366728920000358

Li, L., Abutalebi, J., Emmorey, K., Gong, G., Yan, X., Feng, X., ... Ding, G. (2017). How bilingualism protects the brain from aging: Insights from bimodal bilinguals. Human Brain Mapping, 38(8), 4109-4124. https://doi.org/10.1002/hbm.23652

Lindner, M. (2018). pyBIDSconv. Retrieved from https://github.com/DrMichaelLindner/pyBIDSconv

Lövdén, M., Schaefer, S., Noack, H., Bodammer, N. C., Kühn, S., Heinze, H. J., ... Lindenberger, U. (2012). Spatial navigation training protects the hippocampus against age-related changes during early and late adulthood. Neurobiology of Aging, 33(3), 620.e9-620.e22. https://doi.org/10.1016/j.neurobiolaging.2011.02.013

Luk, G., \& Bialystok, E. (2013). Bilingualism is not a categorical variable: Interaction between language proficiency and usage. Journal of Cognitive Psychology, 25(5), 605621. https://doi.org/10.1080/20445911.2013.795574

Marian, V., \& Shook, A. (2012). The cognitive benefits of being bilingual. Cerebrum: The Dana Forum on Brain Science, 2012, 1-13. https://doi.org/10.1111/j.14679280.2007.01844.x

Mårtensson, J., Eriksson, J., Christian, N., Lindgren, M., Johansson, M., Nyberg, L., ... Lövdén, M. (2012). Growth of language-related brain areas after foreign language learning. NeuroImage, 63(1), 240-244. https://doi.org/10.1016/j.neuroimage.2012.06.043

Miyake, A., Friedman, N. P., Emerson, M. J., Witzki, A. H., Howerter, A., \& Wager, T. D. (2000). The Unity and Diversity of Executive Functions and Their Contributions to Complex "Frontal Lobe" Tasks: A Latent Variable Analysis. Cognitive Psychology, 41(1), 49-100. https://doi.org/10.1006/cogp.1999.0734

Nee, D., \& D’Esposito, M. (2015). Working Memory. In Brain Mapping (Vol. 2, pp. 589595). Elsevier. https://doi.org/10.1016/B978-0-12-397025-1.00050-6

Nyberg, L., Salami, A., Andersson, M., Eriksson, J., Kalpouzos, G., Kauppi, K., ... Nilsson, 
L. G. (2010). Longitudinal evidence for diminished frontal cortex function in aging. Proceedings of the National Academy of Sciences of the United States of America, 107(52), 22682-22686. https://doi.org/10.1073/pnas.1012651108

O’Shea, A., Cohen, R. A., Porges, E. C., Nissim, N. R., \& Woods, A. J. (2016). Cognitive aging and the hippocampus in older adults. Frontiers in Aging Neuroscience, 8(DEC), 1-8. https://doi.org/10.3389/fnagi.2016.00298

Olsen, R. K., Pangelinan, M. M., Bogulski, C., Chakravarty, M. M., Luk, G., Grady, C. L., \& Bialystok, E. (2015). The effect of lifelong bilingualism on regional grey and white matter volume. Brain Research, 1612, 128-139. https://doi.org/10.1016/j.brainres.2015.02.034

Patenaude, B., Smith, S. M., Kennedy, D. N., \& Jenkinson, M. (2011). A Bayesian model of shape and appearance for subcortical brain segmentation. NeuroImage, 56(3), 907-922. https://doi.org/10.1016/j.neuroimage.2011.02.046

Perani, D., \& Abutalebi, J. (2015). Bilingualism, dementia, cognitive and neural reserve. Current Opinion in Neurology, 28(6), 618-625. https://doi.org/10.1097/WCO.0000000000000267

Perneczky, R., Kempermann, G., Korczyn, A. D., Matthews, F. E., Ikram, M. A., Scarmeas, N., ... Ewers, M. (2019). Translational research on reserve against neurodegenerative disease: Consensus report of the International Conference on Cognitive Reserve in the Dementias and the Alzheimer's Association Reserve, Resilience and Protective Factors Professional Interest Ar. BMC Medicine, 17(1), 1-15. https://doi.org/10.1186/s12916$019-1283-z$

Persson, J., Nyberg, L., Lind, J., Larsson, A., Nilsson, L. G., Ingvar, M., \& Buckner, R. L. (2006). Structure-function correlates of cognitive decline in aging. Cerebral Cortex, 16(7), 907-915. https://doi.org/10.1093/cercor/bhj036

Pliatsikas, C. (2020). Understanding structural plasticity in the bilingual brain: The Dynamic Restructuring Model. Bilingualism: Language and Cognition, 23(2), 459-471. https://doi.org/10.1017/S1366728919000130

Pliatsikas, C., DeLuca, V., \& Voits, T. (2020). The Many Shades of Bilingualism: Language Experiences Modulate Adaptations in Brain Structure. Language Learning, 70(S2), 133-149. https://doi.org/10.1111/lang.12386

Pliatsikas, C., Moschopoulou, E., \& Saddy, D. (2017). Brain Structure and Function Immersive late bilingualism reshapes the core of the brain. Brain Structure and Function. https://doi.org/10.1007/s00429-016-1307-9

Ritchie, S. J., Hill, W. D., Marioni, R. E., Davies, G., Hagenaars, S. P., Harris, S. E., ... Deary, I. J. (2019). Polygenic predictors of age-related decline in cognitive ability. Molecular Psychiatry. https://doi.org/10.1038/s41380-019-0372-x

Rönnlund, M., Nyberg, L., Bäckman, L., \& Nilsson, L. G. (2005). Stability, growth, and decline in adult life span development of declarative memory: Cross-sectional and longitudinal data from a population-based study. Psychology and Aging, 20(1), 3-18. https://doi.org/10.1037/0882-7974.20.1.3

Rosselli, M., Loewenstein, D. A., Curiel, R. E., Penate, A., Torres, V. L., Lang, M., ... Duara, R. (2019). Effects of Bilingualism on Verbal and Nonverbal Memory Measures in Mild Cognitive Impairment. Journal of the International Neuropsychological Society, 25(1), 15-28. https://doi.org/10.1017/S135561771800070X

Schroeder, S. R., \& Marian, V. (2012). A bilingual advantage for episodic memory in older adults. Journal of Cognitive Psychology, 24(5), 591-601. https://doi.org/10.1080/20445911.2012.669367

Smith, S. M., Jenkinson, M., Woolrich, M. W., Beckmann, C. F., Behrens, T. E. J., JohansenBerg, H., ... Matthews, P. M. (2004). Advances in functional and structural MR image 
analysis and implementation as FSL. NeuroImage, 23(SUPPL. 1), 208-219. https://doi.org/10.1016/j.neuroimage.2004.07.051

Smith, S. M., \& Nichols, T. E. (2009). Threshold-free cluster enhancement: Addressing problems of smoothing, threshold dependence and localisation in cluster inference. NeuroImage, 44(1), 83-98. https://doi.org/10.1016/j.neuroimage.2008.03.061

Stern, Y., Arenaza-Urquijo, E. M., Bartrés-Faz, D., Belleville, S., Cantilon, M., Chetelat, G., ... Vuoksimaa, E. (2018). Whitepaper: Defining and investigating cognitive reserve, brain reserve, and brain maintenance. Alzheimer's and Dementia, (September), 1-7. https://doi.org/10.1016/j.jalz.2018.07.219

Sullivan, M. D., Prescott, Y., Goldberg, D., \& Bialystok, E. (2016). Executive control processes in verbal and nonverbal working memory: The role of aging and bilingualism. Linguistic Approaches to Bilingualism, 6(1-2), 147-170. https://doi.org/10.1075/lab.15056.sul

Sumowski, J. F., Rocca, M. A., Leavitt, V. M., Riccitelli, G., Meani, A., Comi, G., \& Filippi, M. (2016). Reading, writing, and reserve: Literacy activities are linked to hippocampal volume and memory in multiple sclerosis. Multiple Sclerosis, 22(12), 1621-1625. https://doi.org/10.1177/1352458516630822

Surrain, S., \& Luk, G. (2019). Describing bilinguals: A systematic review of labels and descriptions used in the literature between 2005-2015. Bilingualism: Language and Cognition, 22(2), 401-415. https://doi.org/10.1017/S1366728917000682

Ullman, M. T. (2004). Contributions of memory circuits to language: the declarative/procedural model. Cognition, 92(1-2), 231-270. https://doi.org/10.1016/j.cognition.2003.10.008

Voits, T., Pliatsikas, C., Robson, H., \& Rothman, J. (2019). Beyond Alzheimer' s Disease : Bilingualism and Other Types of Neurodegeneration. PsyArXiv Preprints, 44(0), 0-2. https://doi.org/10.31234/osf.io/5qng4

Weintraub, S., Dikmen, S. S., Heaton, R. K., Tulsky, D. S., Zelazo, P. D., Bauer, P. J., ... Gershon, R. C. (2013). Cognition assessment using the NIH Toolbox. Neurology, 80(Issue 11, Supplement 3), S54-S64. https://doi.org/10.1212/WNL.0b013e3182872ded

Wilson, H., Niccolini, F., Pellicano, C., \& Politis, M. (2019). Cortical thinning across Parkinson's disease stages and clinical correlates. Journal of the Neurological Sciences, 398(July 2018), 31-38. https://doi.org/10.1016/j.jns.2019.01.020

Yaffe, K., Fiocco, A. J., Lindquist, K., Vittinghoff, E., Simonsick, E. M., Newman, A. B., ... Harris, T. B. (2009). Predictors of maintaining cognitive function in older adults: The Health ABC Study. Neurology, 72(23), 2029-2035. https://doi.org/10.1212/WNL.0b013e3181a92c36

Zhang, H., Wu, Y. J., \& Thierry, G. (2020). Bilingualism and aging: A focused neuroscientific review. Journal of Neurolinguistics, 54(June 2019). https://doi.org/10.1016/j.jneuroling.2020.100890 
Tables and figures

Table 1. Demographic information

\begin{tabular}{|c|c|c|c|}
\hline & Monolinguals $(\mathrm{N}=25)$ & Bilinguals $(\mathrm{N}=23)$ & $\begin{array}{l}\text { Overall } \\
(\mathrm{N}=48)\end{array}$ \\
\hline \multicolumn{4}{|l|}{ Age (years) } \\
\hline Mean (SD) & $65.6(10.7)$ & $58.5(6.77)$ & $\begin{array}{l}62.2 \\
(9.62)\end{array}$ \\
\hline \multicolumn{4}{|l|}{ Sex } \\
\hline$F$ & $14(56.0 \%)$ & $16(69.6 \%)$ & $\begin{array}{c}30 \\
(62.5 \%)\end{array}$ \\
\hline M & $11(44.0 \%)$ & $7(30.4 \%)$ & $\begin{array}{c}18 \\
(37.5 \%)\end{array}$ \\
\hline \multicolumn{4}{|c|}{$\begin{array}{l}\text { Education (NIH toolbox } \\
\text { scoring) }\end{array}$} \\
\hline Mean (SD) & $19.1(3.59)$ & $20.5(3.16)$ & $\begin{array}{c}19.8 \\
(3.43)\end{array}$ \\
\hline \multicolumn{4}{|l|}{ First language } \\
\hline English & $25(100 \%)$ & $0(0 \%)$ & $\begin{array}{c}25 \\
(52.1 \%)\end{array}$ \\
\hline Catalan & $0(0 \%)$ & $1(4.3 \%)$ & $1(2.1 \%)$ \\
\hline Croatian & $0(0 \%)$ & $1(4.3 \%)$ & $1(2.1 \%)$ \\
\hline Danish & $0(0 \%)$ & $1(4.3 \%)$ & $1(2.1 \%)$ \\
\hline Dutch & $0(0 \%)$ & $9(39.1 \%)$ & $\begin{array}{c}9 \\
(18.8 \%)\end{array}$ \\
\hline French & $0(0 \%)$ & $1(4.3 \%)$ & $1(2.1 \%)$ \\
\hline German & $0(0 \%)$ & $2(8.7 \%)$ & $2(4.2 \%)$ \\
\hline Italian & $0(0 \%)$ & $1(4.3 \%)$ & $1(2.1 \%)$ \\
\hline Latvian & $0(0 \%)$ & $2(8.7 \%)$ & $2(4.2 \%)$ \\
\hline Polish & $0(0 \%)$ & $1(4.3 \%)$ & $1(2.1 \%)$ \\
\hline Punjabi & $0(0 \%)$ & $1(4.3 \%)$ & $1(2.1 \%)$ \\
\hline Swedish & $0(0 \%)$ & $1(4.3 \%)$ & $1(2.1 \%)$ \\
\hline Ukrainian & $0(0 \%)$ & $2(8.7 \%)$ & $2(4.2 \%)$ \\
\hline \multicolumn{4}{|c|}{$\begin{array}{l}\text { English age of } \\
\text { acquisition (years) } \\
\text { (bilinguals) }\end{array}$} \\
\hline Mean (SD) & & $10.7(6.12)$ & \\
\hline \multicolumn{4}{|c|}{$\begin{array}{l}\text { Length of } \\
\text { immersion/residence in the } \\
\text { UK (years) (bilinguals) }\end{array}$} \\
\hline Mean (SD) & & $29.5(17.2)$ & \\
\hline
\end{tabular}


Table 2. Language scores and proficiency measures

\begin{tabular}{|c|c|c|c|}
\hline & $\begin{array}{l}\text { Monolinguals } \\
\quad(\mathrm{N}=25)\end{array}$ & $\begin{array}{l}\text { Bilinguals } \\
(\mathrm{N}=23)\end{array}$ & $\begin{array}{l}\text { Overall } \\
(\mathrm{N}=48)\end{array}$ \\
\hline \multicolumn{4}{|c|}{ LSBQ L2 Home score } \\
\hline Mean (SD) & $-12.3(2.50)$ & $5.23(4.52)$ & $\begin{array}{l}-3.92 \\
(9.56)\end{array}$ \\
\hline \multicolumn{4}{|c|}{ LSBQ L2 Social score } \\
\hline Mean (SD) & $-6.06(2.86)$ & $51.8(8.40)$ & $21.6(29.8)$ \\
\hline \multicolumn{4}{|c|}{ LSBQ Bilingualism composite score } \\
\hline Mean (SD) & $-5.94(1.58)$ & $17.0(3.43)$ & $5.07(11.9)$ \\
\hline \multicolumn{4}{|c|}{$\begin{array}{l}\text { English proficiency measures } \\
\text { (bilinguals only) }\end{array}$} \\
\hline \multicolumn{4}{|l|}{ Speaking } \\
\hline Mean (SD) & & $8.48(1.28)$ & \\
\hline \multicolumn{4}{|l|}{ Reading } \\
\hline Mean (SD) & & $8.95(0.996)$ & \\
\hline \multicolumn{4}{|l|}{ Writing } \\
\hline Mean (SD) & & $8.47(1.37)$ & \\
\hline \multicolumn{4}{|l|}{ Understanding } \\
\hline Mean (SD) & & $8.82(1.16)$ & \\
\hline
\end{tabular}


Table 3. Cognitive measures and outcomes

\begin{tabular}{lccc}
\hline & $\begin{array}{c}\text { Monolinguals } \\
(\mathbf{N}=\mathbf{2 5})\end{array}$ & Bilinguals (N=23) & $\begin{array}{c}\text { Overall } \\
(\mathbf{N}=48)\end{array}$ \\
\hline $\begin{array}{l}\text { ACE-III total score } \\
\text { Mean (SD) }\end{array}$ & $94.0(4.67)$ & $94.5(3.72)$ & $94.2(4.20)$ \\
$\begin{array}{l}\text { ACE-III memory domain score } \\
\quad \text { Mean (SD) }\end{array}$ & $23.8(2.57)$ & $25.0(1.36)$ & $24.3(2.15)$ \\
$\begin{array}{l}\text { Episodic memory score (NIH toolbox) } \\
\quad \begin{array}{l}\text { Mean (SD) } \\
\text { Working memory score (NIH toolbox) } \\
\quad \text { Mean (SD) }\end{array}\end{array}$ & $96.2(12.4)$ & $103(11.7)$ & $99.3(12.4)$ \\
\hline
\end{tabular}




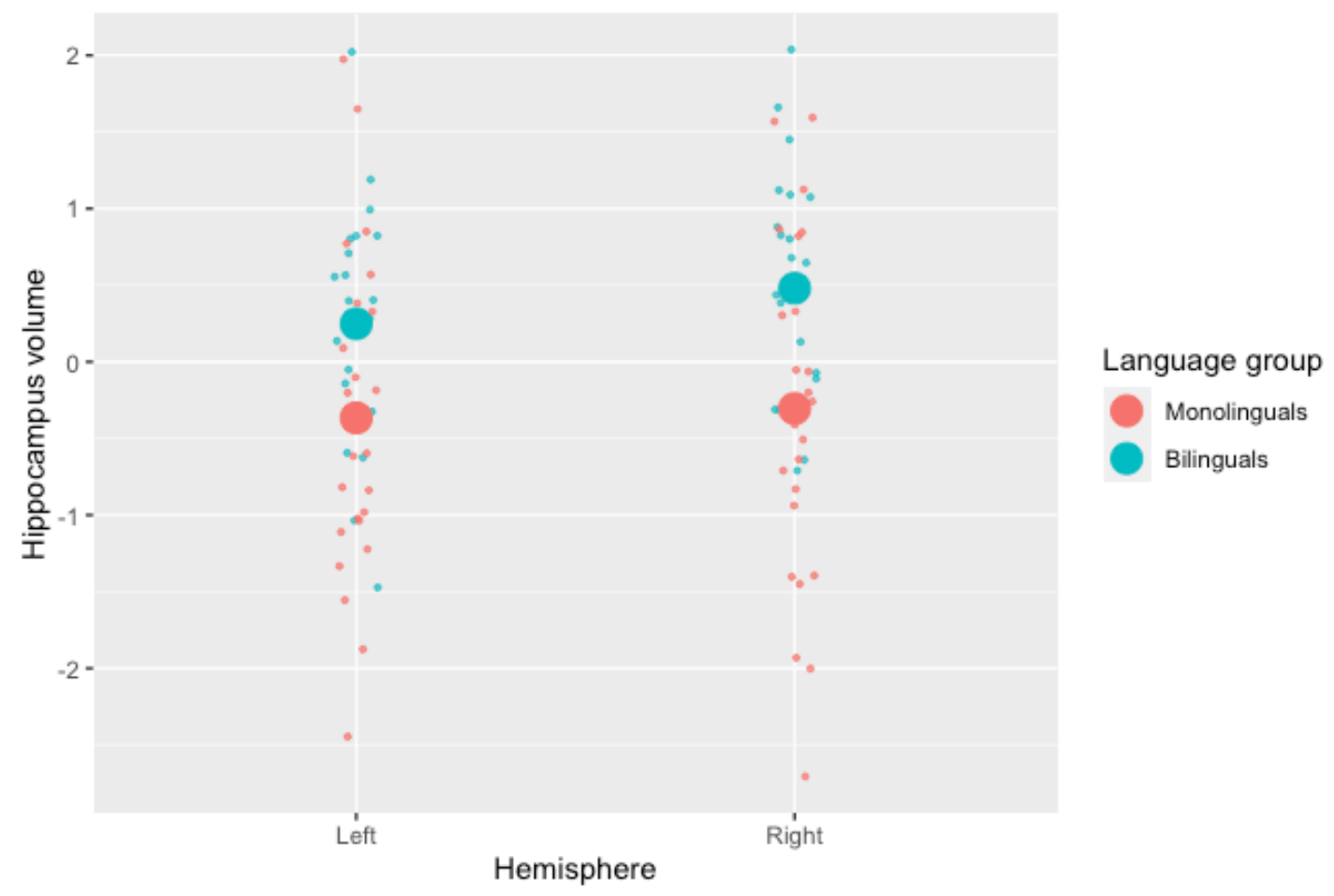

Figure 1. Effect of language group by hemisphere on the hippocampus volume

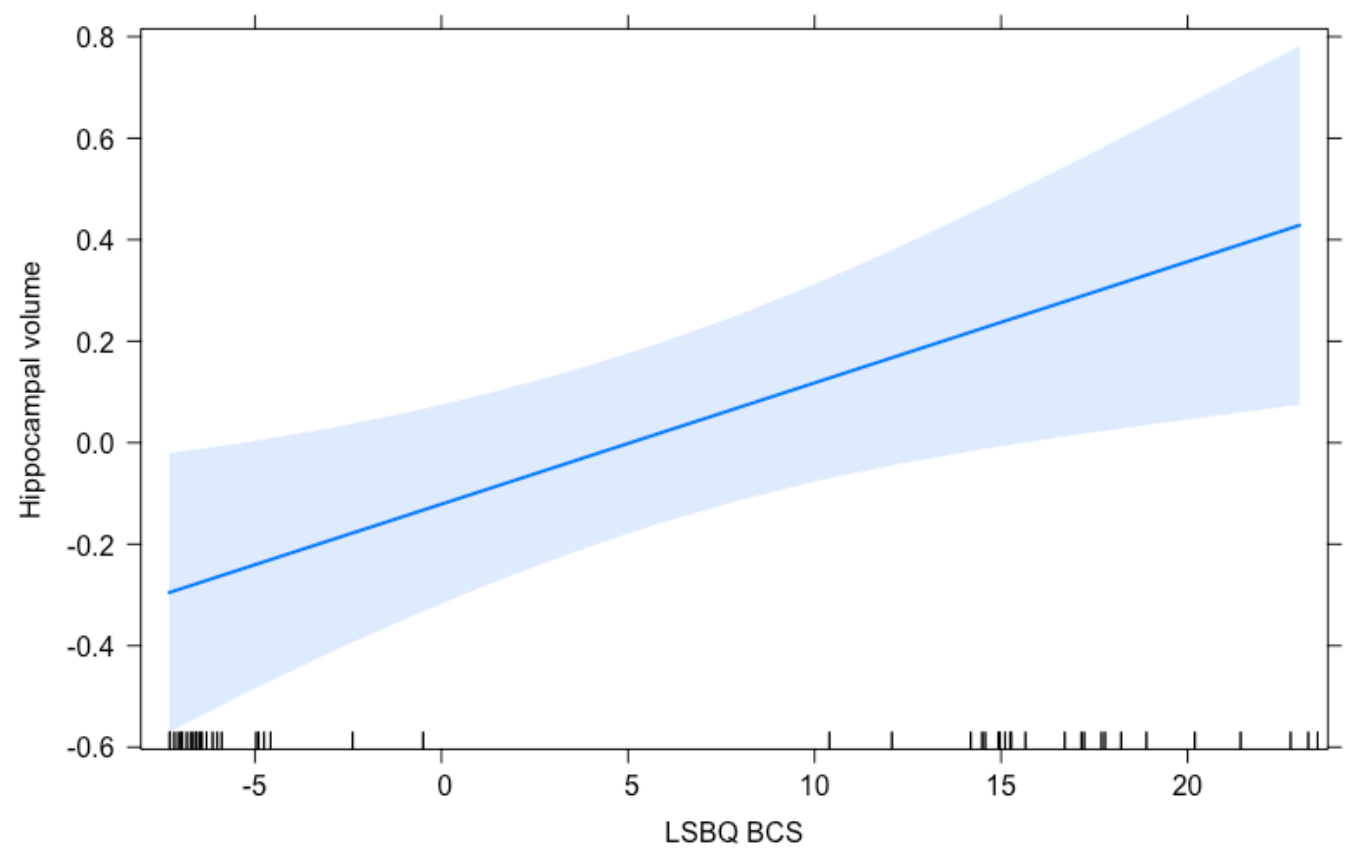

Figure 2. Main effect of the LSBQ Bilingualism Composite Score on the hippocampal volume (Model 3). 
Table 4. Hippocampal volume model comparison.

\begin{tabular}{|c|c|c|c|c|c|c|c|c|c|c|c|c|c|c|c|}
\hline \multirow[b]{2}{*}{ Predictors } & \multicolumn{5}{|c|}{ Model 1} & \multicolumn{5}{|c|}{ Model 2} & \multicolumn{5}{|c|}{ Model 3} \\
\hline & Estimates & std. Error & std. Beta & Statistic & $p$ & Estimates & std. Error & std. Beta & Statistic & $p$ & Estimates & std. Error & std. Beta & Statistic & $p$ \\
\hline Intercept & $-2.599^{\star \star \star}$ & 0.008 & -0.065 & -0.476 & $<0.001$ & $-2.599^{\star \star \star}$ & 0.008 & -0.065 & -0.502 & $<0.001$ & $-2.599^{\star \star \star}$ & 0.007 & -0.065 & -0.522 & $<0.001$ \\
\hline Age & $-0.013^{*}$ & 0.006 & -0.230 & -2.297 & 0.024 & $-0.019^{* *}$ & 0.006 & -0.323 & -3.200 & 0.002 & $-0.014^{*}$ & 0.006 & -0.234 & -2.293 & 0.024 \\
\hline Education & $0.014^{*}$ & 0.006 & 0.232 & 2.319 & 0.023 & $0.018^{* *}$ & 0.006 & 0.303 & 3.095 & 0.003 & $0.016^{* *}$ & 0.006 & 0.278 & 2.943 & 0.004 \\
\hline Hemisphere & 0.008 & 0.011 & 0.130 & 0.673 & 0.503 & 0.008 & 0.011 & 0.130 & 0.710 & 0.479 & 0.008 & 0.010 & 0.130 & 0.738 & 0.462 \\
\hline ACE-III memory performance & & & & & & $0.013^{*}$ & 0.006 & 0.229 & 2.424 & 0.017 & 0.009 & 0.006 & 0.150 & 1.579 & 0.118 \\
\hline $\mathrm{NIH}$ toolbox episodic memory performance & & & & & & $-0.017^{* *}$ & 0.006 & -0.284 & -2.662 & 0.009 & $-0.018^{* *}$ & 0.006 & -0.300 & -2.919 & 0.004 \\
\hline NIH toolbox working memory performance & & & & & & -0.008 & 0.006 & -0.132 & -1.388 & 0.169 & -0.008 & 0.005 & -0.141 & -1.541 & 0.127 \\
\hline LSBQ Bilingualism Composite Score & & & & & & & & & & & $0.017^{* *}$ & 0.006 & 0.289 & 2.867 & 0.005 \\
\hline Observations & 96 & & & & & 96 & & & & & 96 & & & & \\
\hline $\mathrm{R}^{2} / \mathrm{R}^{2}$ adjusted & $0.138 / 0.1$ & & & & & $0.251 / 0.2$ & & & & & $0.315 / 0.2$ & 261 & & & \\
\hline $\mathrm{AIC}$ & -278.580 & & & & & -286.134 & & & & & -292.704 & & & & \\
\hline
\end{tabular}




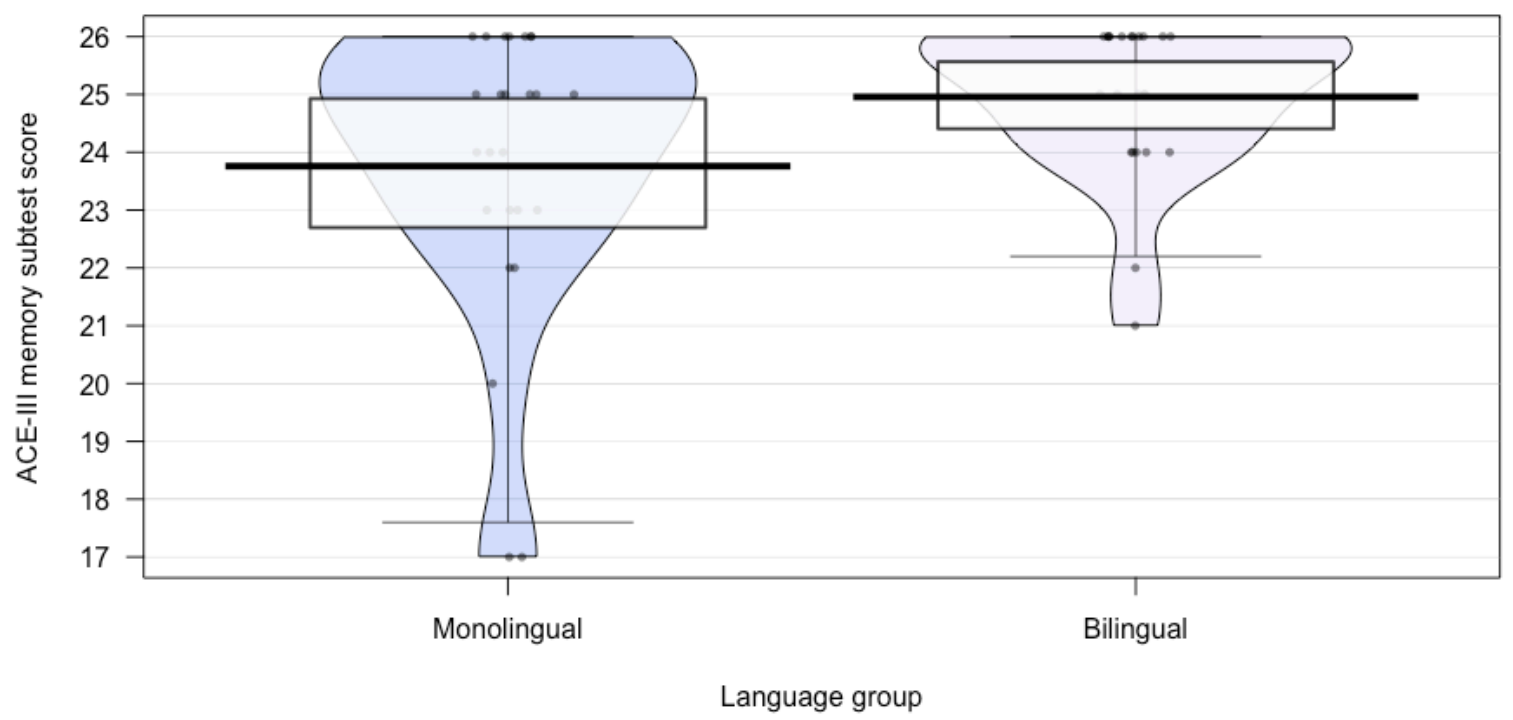

Figure 3. ACE-III memory performance measure by language group

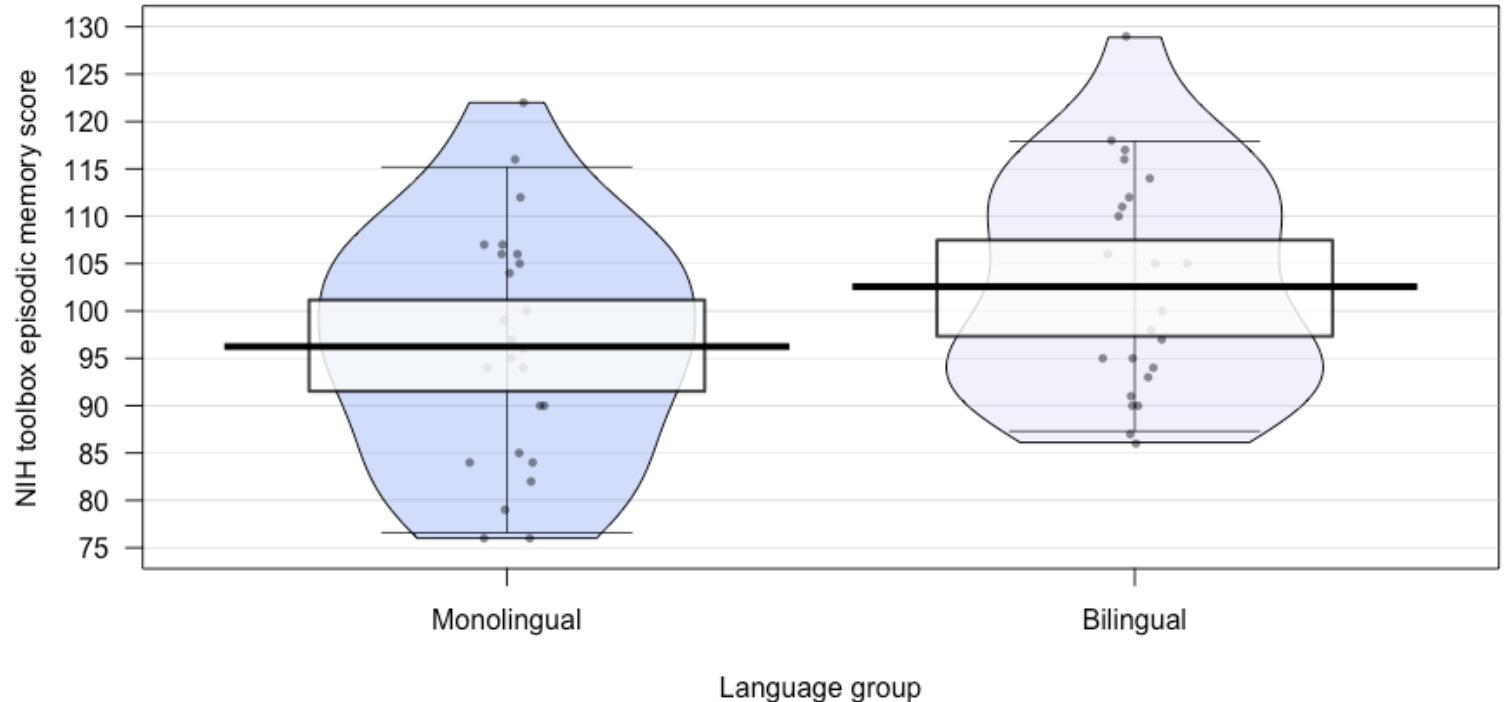

Figure 4. Episodic memory performance by language group 


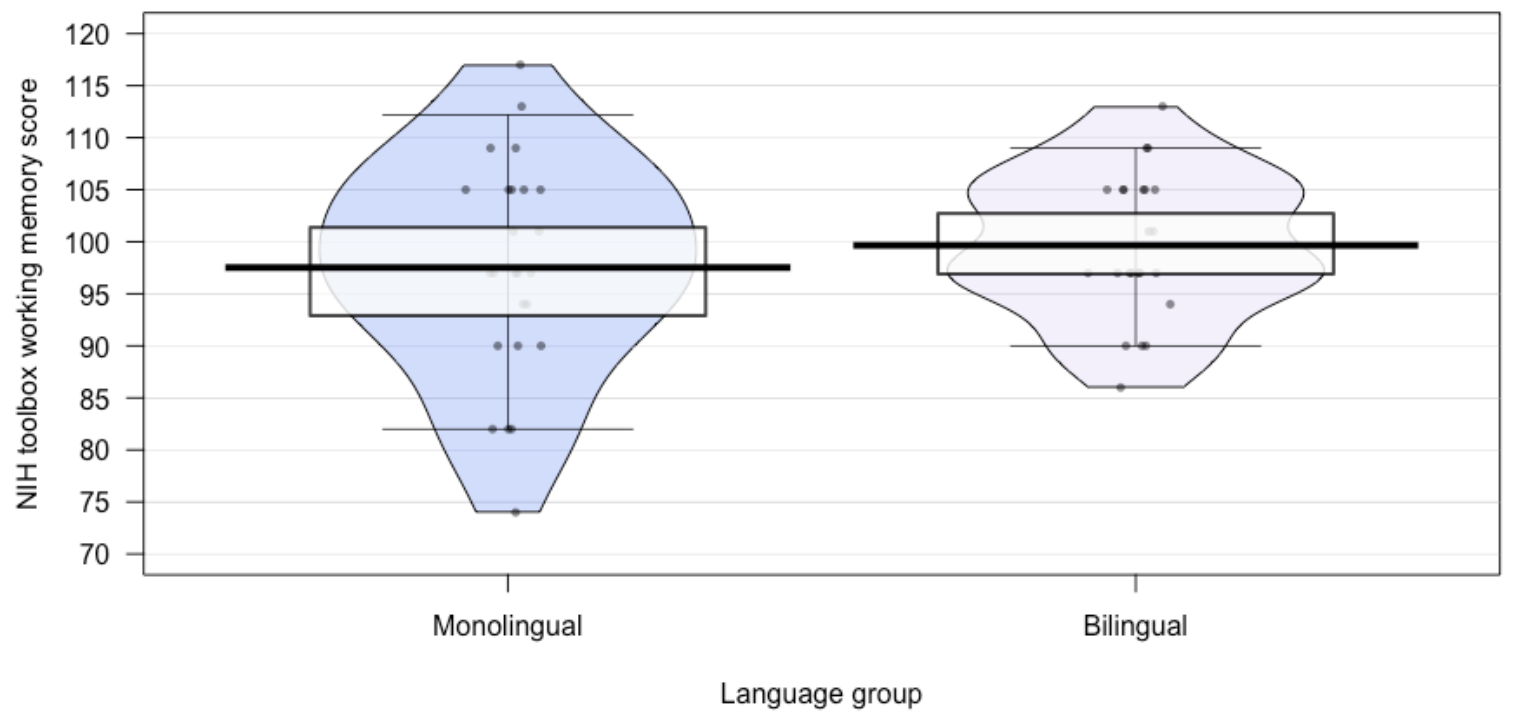

Figure 5. Working memory performance by language group 
Table 5. Behavioural hierarchical regression. Performance in the NIH toolbox working memory task.

\begin{tabular}{|c|c|c|c|c|c|c|c|c|c|c|c|c|c|c|c|}
\hline \multirow[b]{2}{*}{ Predictors } & \multicolumn{5}{|c|}{ Model 4} & \multicolumn{5}{|c|}{ Model 5} & \multicolumn{5}{|c|}{ Model 6} \\
\hline & Estimates & std. Erro & std. Beta & Statistic & $p$ & Estimates & std. Error & std. Beta & Statistic & $p$ & Estimatess & std. Erro & rstd. Beta & Statistic & $p$ \\
\hline Intercept & -0.000 & 0.147 & -0.000 & -0.000 & 1.000 & -0.000 & 0.147 & -0.000 & -0.000 & 1.000 & -0.000 & 0.147 & -0.000 & -0.000 & 1.000 \\
\hline Age & -0.055 & 0.153 & -0.055 & -0.362 & 0.719 & -0.098 & 0.158 & -0.098 & -0.624 & 0.536 & -0.055 & 0.164 & -0.055 & -0.335 & 0.739 \\
\hline Education & 0.106 & 0.153 & 0.106 & 0.694 & 0.491 & 0.149 & 0.158 & 0.149 & 0.943 & 0.351 & 0.143 & 0.158 & 0.143 & 0.905 & 0.371 \\
\hline Hippocampus volume & & & & & & -0.173 & 0.161 & -0.172 & -1.069 & 0.291 & -0.224 & 0.170 & -0.222 & -1.317 & 0.195 \\
\hline LSBQ Bilingualism Composite Score & & & & & & & & & & & 0.165 & 0.168 & 0.165 & 0.980 & 0.333 \\
\hline Observations & 48 & & & & & 48 & & & & & 48 & & & & \\
\hline $\mathrm{R}^{2} / \mathrm{R}^{2}$ adjusted & $0.017 /-0$ & 026 & & & & $0.042 /-0$ & .023 & & & & $0.063 /-0$. & .024 & & & \\
\hline $\mathrm{AIC}$ & 142.881 & & & & & 143.649 & & & & & 144.589 & & & & \\
\hline
\end{tabular}

Table 6. Behavioural hierarchical regression. Performance in the NIH toolbox episodic memory task.

\begin{tabular}{|c|c|c|c|c|c|c|c|c|c|c|c|c|c|c|c|}
\hline \multirow[b]{2}{*}{ Predictors } & \multicolumn{5}{|c|}{ Model 4} & \multicolumn{5}{|c|}{ Model 5} & \multicolumn{5}{|c|}{ Model 6} \\
\hline & Estimates & std. Errol & std. Beta & Statistic & $p$ & Estimates s & std. Erro & std. Beta & Statistic & $p$ & Estimatess & std. Erro & rorstd. Beta & Statistic & $p$ \\
\hline Intercept & 0.000 & 0.132 & 0.000 & 0.000 & 1.000 & 0.000 & 0.128 & 0.000 & 0.000 & 1.000 & 0.000 & 0.127 & 0.000 & 0.000 & 1.000 \\
\hline Age & $-0.338^{*}$ & 0.137 & -0.338 & -2.463 & 0.018 & $-0.406^{\star \star}$ & 0.138 & -0.406 & -2.939 & 0.005 & $-0.348^{*}$ & 0.141 & -0.348 & -2.460 & 0.018 \\
\hline Education & 0.229 & 0.137 & 0.229 & 1.669 & 0.102 & $0.296^{*}$ & 0.138 & 0.296 & 2.143 & 0.038 & $0.288^{*}$ & 0.136 & 0.288 & 2.116 & 0.040 \\
\hline Hippocampus volume & & & & & & -0.270 & 0.141 & -0.268 & -1.908 & 0.063 & $-0.337^{*}$ & 0.146 & -0.336 & -2.307 & 0.026 \\
\hline LSBQ Bilingualism Composite Score & & & & & & & & & & & 0.220 & 0.145 & 0.220 & 1.517 & 0.137 \\
\hline Observations & 48 & & & & & 48 & & & & & 48 & & & & \\
\hline$R^{2} / R^{2}$ adjusted & $0.206 / 0$ & & & & & $0.267 / 0.2$ & & & & & $0.304 / 0.2$ & 239 & & & \\
\hline AIC & 132.647 & & & & & 130.833 & & & & & 130.331 & & & & \\
\hline
\end{tabular}


Table 7. Behavioural hierarchical regression. Performance in the ACE-III memory domain.

\begin{tabular}{|c|c|c|c|c|c|c|c|c|c|c|c|c|c|c|c|}
\hline \multirow[b]{2}{*}{ Predictors } & \multicolumn{5}{|c|}{ Model 4} & \multicolumn{5}{|c|}{ Model 5} & \multicolumn{5}{|c|}{ Model 6} \\
\hline & Estimates & std. Erro & std. Beta & Statistic & $p$ & Estimates & std. Erro & rorstd. Beta & a Statistic & $p$ & Estimatess & std. Errol & rstd. Beta & Statistic & $p$ \\
\hline Intercept & 0.000 & 0.148 & -0.000 & -0.000 & 1.000 & 0.000 & 0.148 & -0.000 & -0.000 & 1.000 & 0.000 & 0.143 & -0.000 & -0.000 & 1.000 \\
\hline Age & -0.043 & 0.154 & -0.043 & -0.282 & 0.779 & 0.002 & 0.159 & 0.002 & 0.015 & 0.988 & 0.085 & 0.160 & 0.085 & 0.529 & 0.599 \\
\hline Education & 0.036 & 0.154 & 0.036 & 0.236 & 0.814 & -0.009 & 0.158 & -0.009 & -0.056 & 0.956 & -0.020 & 0.154 & -0.020 & -0.129 & 0.898 \\
\hline Hippocampus volume & & & & & & 0.183 & 0.162 & 0.182 & 1.127 & 0.266 & 0.087 & 0.166 & 0.086 & 0.523 & 0.604 \\
\hline LSBQ Bilingualism Composite Score & & & & & & & & & & & 0.312 & 0.164 & 0.312 & 1.900 & 0.064 \\
\hline Observations & 48 & & & & & 48 & & & & & 48 & & & & \\
\hline $\mathrm{R}^{2} / \mathrm{R}^{2}$ adjusted & $0.004 /-c$ & 040 & & & & $0.032 /-0$ & 0.034 & & & & $0.107 / 0.0$ & 024 & & & \\
\hline AIC & 143.524 & & & & & 144.158 & & & & & 142.291 & & & & \\
\hline
\end{tabular}

